\title{
Synthesis and Radical Polymerization of $p$-Phenylselenomethylstyrene and Applications to Graft Copolymers
}

\author{
Tae Seok Kwon, Shuji Kondo, ${ }^{\dagger}$ Koji Takagi, Hideo Kunisada, \\ and Yasuo $\mathrm{YUKI}^{\dagger \dagger}$ \\ Department of Materials Science and Engineering, \\ Nagoya Institute of Technology, Gokiso-cho, Showa-ku, Nagoya 466-8555, Japan
}

(Received August 18, 1998)

\begin{abstract}
Phenylselenomethylstyrene (1) as a new selenium-containing vinyl monomer was prepared. It was readily polymerized free radically in the presence of $2,2^{\prime}$-azobis(isobutyronitrile) (AIBN) as initiator at $60^{\circ} \mathrm{C}$ to afford corresponding homopolymers having number-average molecular weights of about 8600 . From the copolymerization of 1 with styrene, $Q$ and $e$ of 1 were 1.40 and -1.06 , respectively. Photoirradiation of the copolymer of styrene and 1 in the presence of methyl methacrylate effectively afforded a graft copolymer composed of a polystyrene backbone and poly(methyl methacrylate) branches.

KEY WORDS Free Radical Polymerization / p-Phenylselenomethylstyrene / Selenium-Containing Polymer / Polymeric Photoiniferter / Graft Copolymer /
\end{abstract}

Organoselenium compounds are very useful in organic synthesis. ${ }^{1-3}$ However, most of these compounds stink and are toxic. To solve these problems, the synthesis of polymers containing selenium at main or side chain has been studied. ${ }^{4-12}$ We reported the synthesis of selenium-containing monomers such as $p$-methylselenostyrene and $p$-phenylselenostyrene, and their homopolymerization and copolymerization with styrene. ${ }^{13} \mathrm{We}$ also reported the synthesis of end functional polystyrene by radical polymerization in the presence of benzyl phenyl selenide (BPSE) as a photoiniferter. ${ }^{14}$ The resulting polystyrene (PST) had benzyl and phenylseleno groups at $\alpha$ - and $\omega$-chain ends, respectively. Photoirradiation of this end functional polystyrene as a polymeric photoiniferter in the presence of methyl methacrylate (MMA) effectively afforded a block copolymer (PST- $b$ PMMA) of styrene and MMA (eq 1).

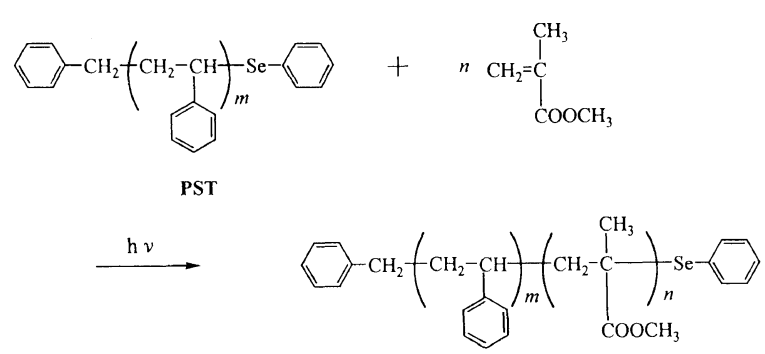

PST-b-PMMA

A photoiniferter is used for graft copolymerization. ${ }^{15}$ Because of the high graft efficiency, this method is very effective for the preparation of functional polymers. ${ }^{16}$ Otsu et al. ${ }^{17,18}$ reported the preparation of graft copolymers using polymeric photoiniferter containing $N, N$-diethyldithiocarbamate moiety. Niwa et al. ${ }^{19}$ prepared the graft copolymer from photosensitive xanthate.

This paper reports the synthesis of $p$-phenylselenomethylstyrene (1) as a new selenium-containing vinyl monomer, and its homo- and copolymerization behavior.
We expected the photoiniferter containing selenium in polymer at side chain to afford a well-defined graft copolymer. We describe the synthesis of graft copolymer (PG) by radical polymerization of copolymer containing 1 with styrene (PC) in the presence of MMA under photoirradiation (eq 2).
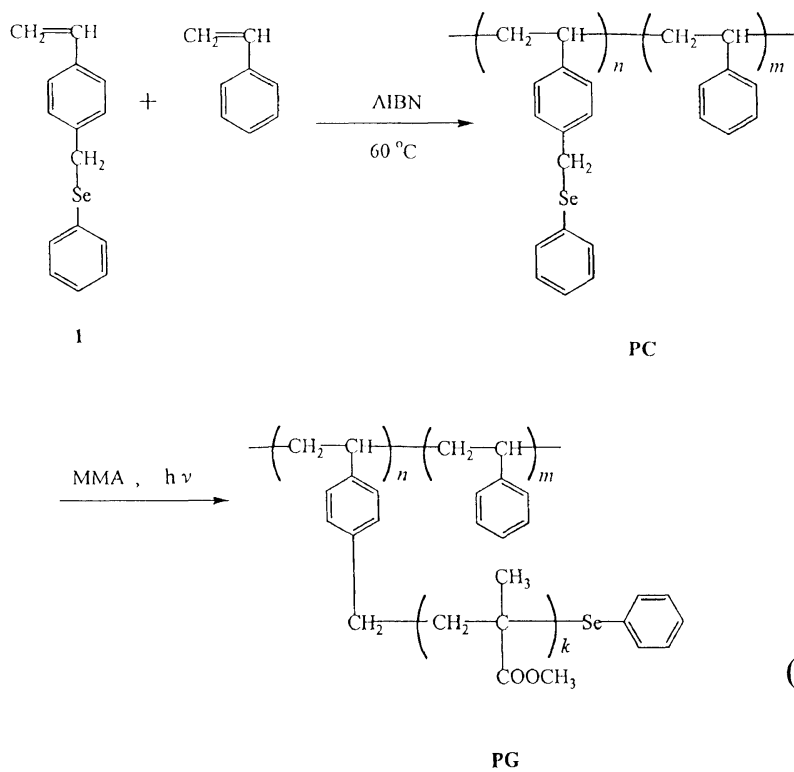

\section{EXPERIMENTAL}

\section{Materials}

Styrene and MMA were purified and distilled by the ordinary method before use. 2,2'-Azobisisobutyronitrile (AIBN) was recrystallized twice from methanol. Other reagents and solvents were used after ordinary purification.

Synthesis of p-Phenylselenomethylstyrene (1)

To a solution of $p$-phenylmagnesium bromide prepared

\footnotetext{
$\dagger$ Deceased August 5, 1997.

${ }^{\dagger+}$ To whom all correspondence should be addressed (Fax: +81-52-735-5294)
} 
from magnesium $(4.8 \mathrm{~g}, 0.2 \mathrm{~mol})$ and bromobenzene $(31.2 \mathrm{~g}, 0.2 \mathrm{~mol})$ in anhydrous ether $(60 \mathrm{ml})$, selenium powder $(14.8 \mathrm{~g}, 0.2 \mathrm{~mol})$ was added gradually over $1 \mathrm{~h}$. Stirring was continued for $2 \mathrm{~h}$ at room temperature. To this reaction mixture, $p$-chloromethylstyrene $(29.5 \mathrm{~g}$, $0.2 \mathrm{~mol}$ ) was added slowly with cooling, and the mixture was stirred at room temperature for $8 \mathrm{~h}$. The reaction mixture was poured into a solution of $2 \%$ ammonium chloride $(200 \mathrm{ml})$ and extracted with ether. The extract was dried over anhydrous sodium sulfate. After evaporation of the solvent, the product was recrystallized from ethanol. Yield was $17.9 \mathrm{~g}(34.3 \%), \mathrm{mp} 58^{\circ} \mathrm{C}$.

${ }^{1} \mathrm{H} \mathrm{NMR}$ (in $\mathrm{CDCl}_{3}$ ): $\delta 4.10\left(\mathrm{~s}, \mathrm{CH}_{2}, 2 \mathrm{H}\right), 5.20(\mathrm{~d}$, trans $\left.-\mathrm{CH}_{2}=, 1 \mathrm{H}\right), 5.70\left(\mathrm{~d}\right.$, cis $\left.-\mathrm{CH}_{2}=, 1 \mathrm{H}\right), 6.70(\mathrm{dd}$, $=\mathrm{CH}, 1 \mathrm{H})$, and $7.20-7.46\left(\mathrm{~m}, \mathrm{C}_{6} \mathrm{H}_{4}\right.$ and $\left.\mathrm{C}_{6} \mathrm{H}_{5}, 9 \mathrm{H}\right)$

IR (KBr): $v_{-}{ }_{\mathrm{CH}}=\mathrm{CH}_{2}=995 \mathrm{~cm}^{-1}$

UV (in ethanol): $\lambda_{\max }=260.4 \mathrm{~nm}\left(\varepsilon=3.3 \times 10^{4}\right)$

Anal. Calcd for $\mathrm{C}_{15} \mathrm{H}_{14} \mathrm{Se}: \mathrm{C}, 65.94 \% ; \mathrm{H}, 5.16 \%$. Found: $\mathrm{C}, 65.86 \% ; \mathrm{H}, 5.21 \%$

\section{Homopolymerization of $\mathbf{1}$}

A solution of $1(1.37 \mathrm{~g}, 5 \mathrm{mmol})$, AIBN $(0.0086 \mathrm{~g}$, $0.05 \mathrm{mmol})$ and benzene $(2.5 \mathrm{ml})$ were mixed in an ample tube. The tube was degassed under vacuum by conventional freezing and thawing and sealed off under vacuum. Polymerization was carried out for $20 \mathrm{~h}$ at $60^{\circ} \mathrm{C}$. After polymerization, the mixture was poured into excess hexane to precipitate the polymer. The resulting polymer (P1) was reprecipitated from methylene chloride into hexane, followed by drying in vacuum. Yield was $0.48 \mathrm{~g}$ $(35.2 \%)$.

\section{Copolymerization of $\mathbf{1}$ with Styrene}

Monomer 1, styrene, AIBN (1 mol\%) and benzene were mixed in an ample tube. The tube was degassed under vacuum by conventional freezing and thawing, and sealed off under vacuum. Polymerization was carried out at $60^{\circ} \mathrm{C}$. Polymer yields were kept below $10 \%$ in the case of evaluation of copolymerization parameters. After polymerization, the mixture was poured into excess methanol to precipitate the polymer. The polymer (PC) was reprecipitated from methylene chloride into methanol, followed by drying in vacuum. The composition of the copolymer was found based on methylene signals of 1 at $4.0 \mathrm{ppm}$ with phenyl and phenylene signals of styrene and 1 at $6.3-7.5 \mathrm{ppm}$ in ${ }^{1} \mathrm{H}$ NMR spectrum.

\section{Synthesis of Graft Copolymer from PC with $M M A$}

A sample of PC $(0.20 \mathrm{~g})$, MMA $(3.0 \mathrm{ml})$ and benzene $(2 \mathrm{ml})$ in Pyrex tube was irradiated with $100 \mathrm{~W}$ highpressure mercury lamp at room temperature for 3 or $5 \mathrm{~h}$. The polymerization mixture was poured into methanol. Poly(MMA) was separated from the polymer (gross polymer) by fractional precipitation with benzene and methanol. The PG was dried in vaccum. The polymer fractions were examined by ${ }^{1} \mathrm{H}$ NMR spectra. Conversion of MMA was calculated as,

$$
\text { Conversion }(\%)=[(A-B) / C] \times 100
$$

where $A$ is weight of gross polymer, $B$ is weight of prepolymer $(0.20 \mathrm{~g})$, and $C$ is weight of MMA $(2.81 \mathrm{~g})$. Grafting and graft efficiency in this polymerization condition were determined by,

$$
\begin{gathered}
\text { Grafting }(\%)=[(D-B) / B] \times 100 \\
\text { Graft efficiency }(\%)=[(D-B) /(A-B)] \times 100
\end{gathered}
$$

where $D$ is weight of the graft copolymer.

\section{Measurements}

${ }^{1} \mathrm{H}$ NMR spectra were recorded by a JEOL JNM GX400 (400 MHZ) spectrometer with $\mathrm{CDCl}_{3}$ as solvent using tetramethylsilane as the internal standard. Gel permeation chromatography (GPC) was performed on a TOSOH HLC-803D with G2000, G3000, and GMH TSK gel-columns and differential refractometric detector using tetrahydrofuran (THF) as eluent. Molecular weights were determined using polystyrene standards. Differential scanning calorimetry (DSC) was performed on a Rigaku Denki DSC-8230 at a heating rate of

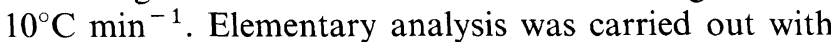
Yanaco CHN CORDER MT-3. IR spectra were measured by a Nicolet Impact-400D and UV spectra were taken in ethanol by a JASCO Ubest-35 spectrometer.

\section{RESULTS AND DISCUSSION}

\section{Homopolymerization}

The homopolymerization of 1 was carried out at $60^{\circ} \mathrm{C}$ for $20 \mathrm{~h}$ using AIBN as the initiator in benzene. Yield of the polymer (P1) was $35.2 \%$, and number-average molecular weight $\left(\bar{M}_{n}\right), 8600\left(\bar{M}_{w} / \bar{M}_{n}=2.17\right)$. Compared with 1 , styrene was polymerized at the same conditions. Polystyrene yield was $52 \%\left(\bar{M}_{w}=24500, \bar{M}_{n}=16300\right.$, and $\left.\bar{M}_{w} / \bar{M}_{n}=1.50\right)$. Chain transfer reaction thus occurred for 1. In the IR spectrum of P1, the absorption band due to vinyl group at $995 \mathrm{~cm}^{-1}$ was absent. In the ${ }^{1} \mathrm{H}$ NMR spectrum of P1, signals of vinyl protons completely disappeared, and new signals at $1.1-2.1 \mathrm{ppm}$ due to methylene and methine protons of polymer main chain appeared (Figure 1). The structure of this polymer was also confirmed by comparing the peak area of methylene protons of benzyl group at $4.0 \mathrm{ppm}$ to that of phenyl protons at $6.2-7.5 \mathrm{ppm}$ and that of protons in main chain at $1.1-2.1 \mathrm{ppm}$. The polymer was soluble in benzene, chloroform, THF, and dimethylsulfoxide, but insoluble in $n$-hexane and methanol. The glass transition temperature $\left(T_{\mathrm{g}}\right)$ of $\mathbf{P 1}$ was determined by DSC to be $33^{\circ} \mathrm{C}$.

\section{Copolymerization}

Reactivity of the monomer in radical copolymerization with styrene was investigated. The copolymerization of 1 with styrene at various compositions was carried out at $60^{\circ} \mathrm{C}$ using AIBN as initiator in benzene. Polymer yield was kept below $10 \%$ to evaluate copolymerization parameters. The results are shown in Table I.

Figure 2 shows the monomer-copolymer composition curve for $1\left(M_{1}\right)$ with styrene $\left(M_{2}\right)$. The curve indicated essentially ideal copolymerization along the azeotropic line. Monomer reactivity ratios $\left(r_{1}, r_{2}\right)$ calculated by the Fineman-Ross method, ${ }^{20}$ and Alfrey-Price ${ }^{21} Q$ and $e$ are shown in Table II together with values for related monomers. Parameters for 1 were similar to those for $p$-methylstyrene. ${ }^{22,23}$ In Table II, $e$ of $p$-phenylselenostyrene and $p$-methylselenostyrene have selenium com- 


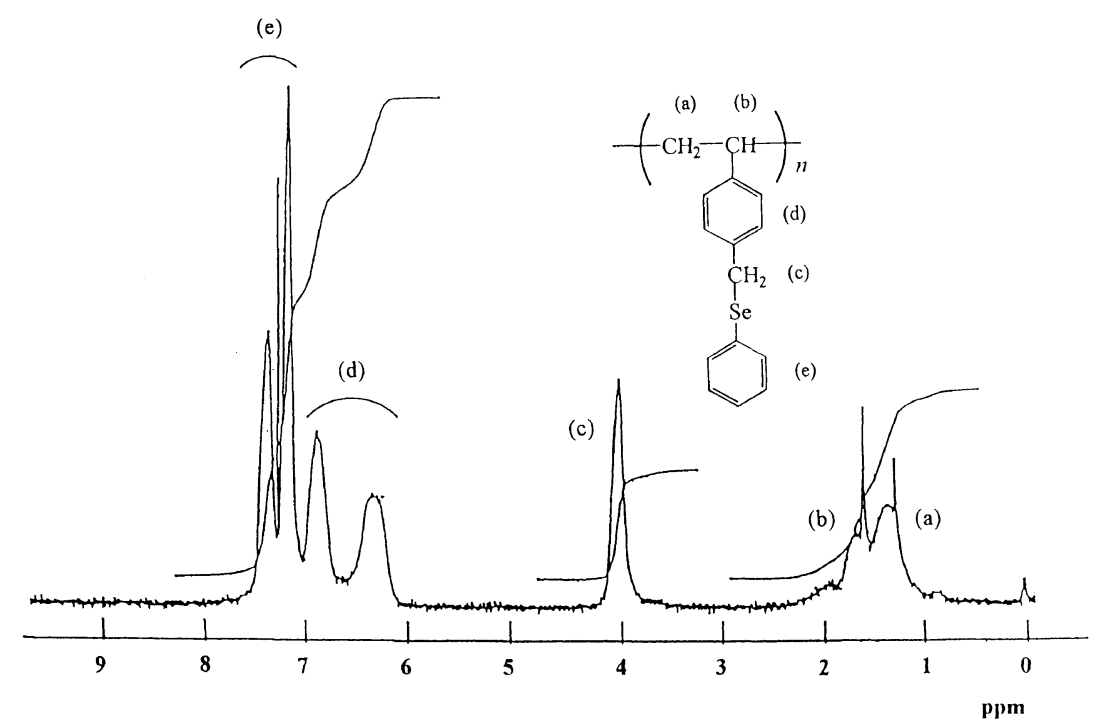

Figure 1. ${ }^{1} \mathrm{H}$ NMR spectrum $\left(400 \mathrm{MHz}\right.$, in $\left.\mathrm{CDCl}_{3}\right)$ of $\mathbf{P 1}$.

Table I. Copolymerization a $1\left(M_{1}\right)$ with styrene $\left(M_{2}\right)$

\begin{tabular}{|c|c|c|c|c|c|}
\hline$M_{1}^{\mathrm{b}}$ & Time & Conversion & $m_{1}{ }^{\mathrm{c}}$ & & \\
\hline $\mathrm{mol} \%$ & $\mathrm{~h}$ & $\%$ & $\mathrm{~mol} \%$ & & \\
\hline 15 & 2.0 & 7.3 & 16.6 & 8800 & 1.74 \\
\hline 30 & 2.5 & 8.9 & 31.8 & 7800 & 2.14 \\
\hline 40 & 2.5 & 8.9 & 43.3 & 7600 & 1.72 \\
\hline 45 & 2.5 & 7.2 & 46.6 & 7200 & 1.88 \\
\hline 55.5 & 2.5 & 9.1 & 53.1 & - & - \\
\hline 85 & 2.5 & 0.3 & 88.2 & - & - \\
\hline
\end{tabular}

${ }^{\mathrm{a}} \mathbf{1}+$ styrene $=10 \mathrm{mmol} ;[\mathrm{AIBN}]=0.1 \mathrm{mmol} ;$ solvent, benzene $(5 \mathrm{ml})$ at $60^{\circ} \mathrm{C}$. ${ }^{\mathrm{b}}$ Mole fraction of 1 in the monomer mixture. ${ }^{\mathrm{c}}$ Mole fraction of 1 in the copolymer calculated by ${ }^{1} \mathrm{H}$ NMR.

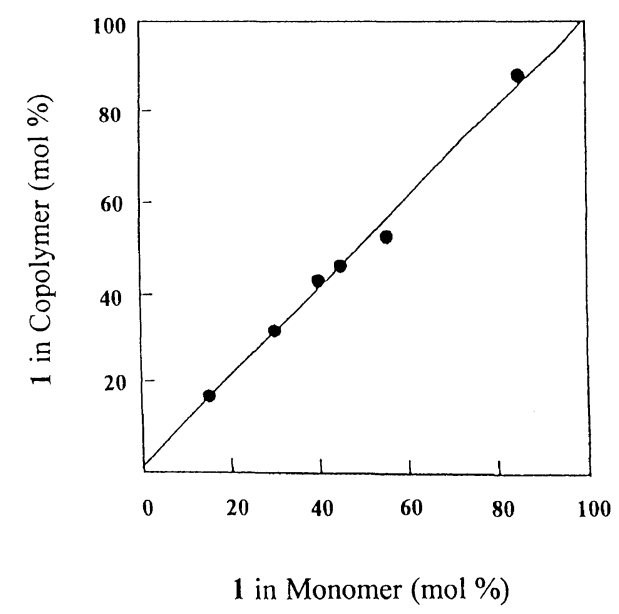

Figure 2. Monomer-copolymer composition curve for $1\left(\mathrm{M}_{1}\right)$ and styrene $\left(\mathrm{M}_{2}\right)$.

bined directly to $p$-position in styrene were changed significantly compared with that of styrene. The effects of phenylselenomethyl group on the monomer reactivity appeared essentially same as those of the methyl group at the initial stage.

\section{Graft Copolymerization}

The graft copolymerization of poly(1-co-styrene) (PC) with MMA was carried out in benzene under
Table II. Copolymerization parameters ${ }^{\mathrm{a}}$

\begin{tabular}{cccccc}
\hline $\mathrm{M}_{1}$ & $r_{1}$ & $r_{2}$ & $Q_{1}$ & $e_{1}$ & ref \\
\hline 1 & 1.06 & 0.88 & 1.40 & -1.06 & This work \\
$\begin{array}{c}\text { 1 } \\
\text {-Phenylselenostyrene }\end{array}$ & 1.22 & 0.48 & 1.03 & -0.04 & 13 \\
-Methylselenostyrene & 1.35 & 0.54 & 1.18 & -0.24 & 13 \\
$p$-Methylstyrene & 1.15 & 0.82 & 1.48 & -1.04 & 22 \\
\hline
\end{tabular}

${ }^{\text {a }}$ Copolymerization with styrene $\left(\mathrm{M}_{2}\right)$.

photoirradiation at low conversion of MMA $(\leqq 30 \%)$ because of the low-end functionality $(D F=0.5-0.6)$ for MMA. $^{24}$ The results are shown in Table III. The polymerization proceeded in the presence of $\mathrm{PC}$ with the production of homopolymer of MMA possibly generated by photoirradiation regardless of the polymeric initiator. The graft copolymers were isolated in high yields by fractional precipitation using benzene and methanol. Residual PC was not found in only fraction as confirmed by ${ }^{1} \mathrm{H}$ NMR and GPC. GPC curves of the prepolymer and graft copolymer are shown in Figure 3. The curve of graft copolymer showed an unimodal peak. Graft efficiency and grafting slightly increased with the content of 1 in the prepolymers. This shows that PC functions effectively as a polymeric photoiniferter and MMA is inserted between selenium and the polymer radical generated by photoirradiation. Graft copolymers formed by the same mechanism as in case of block copolymers in the previous work. ${ }^{14}$

Figure 4 shows ${ }^{1} \mathrm{H}$ NMR of the isolated graft copolymer, PG-1. The spectrum contains signals assigned to PST and PMMA segments. All graft copolymers showed signals similar to that of PG-1. The composition of the graft copolymers was determined from ${ }^{1} \mathrm{H}$ NMR by comparing relative ratios of methoxy protons of MMA unit at $3.7 \mathrm{ppm}$ and phenyl protons of styrene unit at 6.3-7.2 ppm. Composition was estimated from molecular weight $\left(\bar{M}_{n}\right)$ measured by GPC. The summarized in Table IV. The compositions agreed satisfactorily with each other, irrespective of the method of determination. The composition of MMA in the graft copolymer indicated grafting to increase with $\mathbf{1}$ in the 
Table III. Preparation of styrene--methyl methacrylate graft copolymers (PG)

\begin{tabular}{|c|c|c|c|c|c|c|c|c|c|c|c|}
\hline \multicolumn{4}{|c|}{ Prepolymer } & \multirow{3}{*}{$\frac{\text { Time }}{\mathrm{h}}$} & \multirow{3}{*}{$\frac{\begin{array}{c}\text { Total } \\
\text { yield }^{\mathrm{c}}\end{array}}{\mathrm{g}}$} & \multirow{3}{*}{$\begin{array}{c}\begin{array}{c}\text { Conversion }^{\mathrm{d}} \\
\text { of MMA }\end{array} \\
\%\end{array}$} & \multicolumn{2}{|c|}{ Graft copolymerization } & \multirow{3}{*}{$\frac{\text { Grafting }}{\%}$} & \multirow{3}{*}{$\frac{\begin{array}{c}\text { Graft } \\
\text { efficiency }\end{array}}{\%}$} & \multirow{3}{*}{$\begin{array}{c}\text { Graft } \\
\text { copolymer }\end{array}$} \\
\hline \multirow{2}{*}{$\mathrm{PC}$} & $\mathrm{d}[\mathbf{1}]^{\mathrm{b}}$ & & & & & & Homo PMMA ${ }^{\mathrm{e}}$ & Graft copolymer & & & \\
\hline & $\mathrm{mol} \%$ & $M_{n} / 10$ & $M_{w} / M_{n}$ & & & & $\mathrm{~g} / \mathrm{wt} \%$ & $\mathrm{~g} / \mathrm{wt} \%$ & & & \\
\hline PC-1 & 3 & 1.13 & 1.75 & 3 & 0.90 & 25.0 & $0.14 / 16.0$ & $0.76 / 84.0$ & 280 & 80 & PG-1 \\
\hline PC-2 & 5 & 0.98 & 1.98 & 3 & 1.00 & 28.3 & $0.15 / 14.6$ & $0.85 / 85.4$ & 325 & 81 & PG-2 \\
\hline PC-3 & 11 & 1.03 & 2.07 & 3 & 0.82 & 22.0 & $0.08 / 10.3$ & $0.74 / 89.7$ & 270 & 87 & PG-3 \\
\hline PC-3 & 11 & 1.03 & 2.07 & 5 & 0.97 & 27.4 & $0.10 / 10.0$ & $0.87 / 90.0$ & 335 & 87 & PG-4 \\
\hline
\end{tabular}

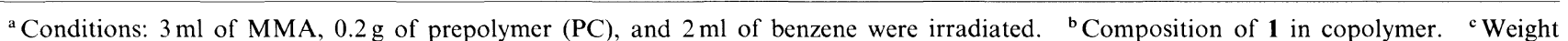
of polymer precipitated with methanol (gross polymer). ${ }^{\mathrm{d}}$ (Weight of polymer precipitated-Weight of prepolymer)/Weight of monomer charged) $\times 100$. ${ }^{\mathrm{e}}$ Extracted with the mixture solvent of benzene and methanol.

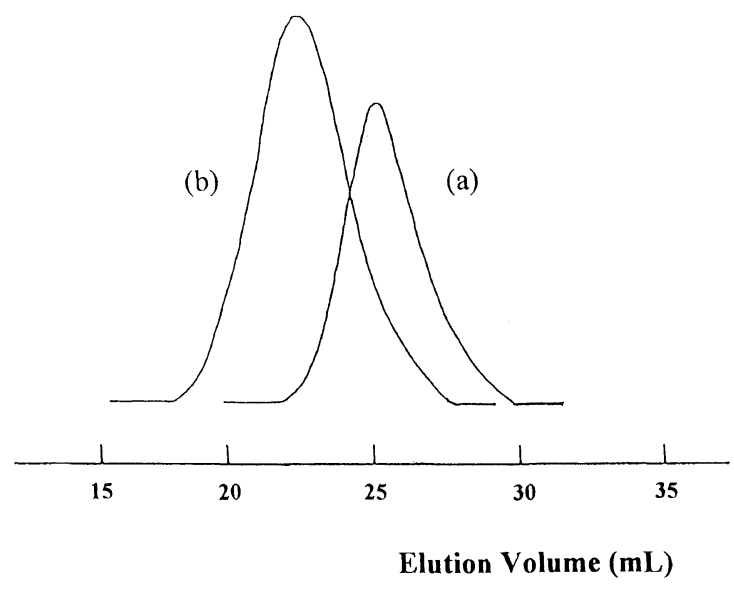

Figure 3. GPC profiles of (a) PC-3 $\left(\bar{M}_{n}=10300, \bar{M}_{w} / \bar{M}_{n}=2.07\right)$ as a prepolymer and (b) PG-4 $\left(\bar{M}_{n}=42300, \bar{M}_{w} / \bar{M}_{n}=2.49\right)$.

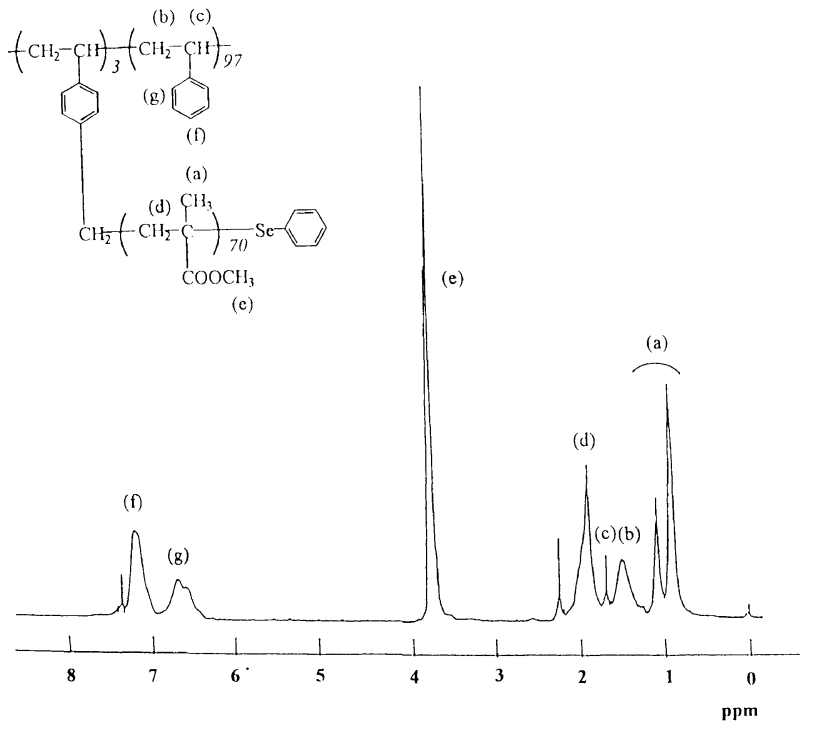

Figure 4. ${ }^{1} \mathrm{H}$ NMR spectrum $\left(400 \mathrm{MHz}^{\text {, in }} \mathrm{CDCl}_{3}\right)$ of $\mathrm{PG}-1$.

Table IV. Characterization of the graft copolymers

\begin{tabular}{|c|c|c|c|c|c|}
\hline \multicolumn{3}{|c|}{ Graft copolymer } & \multicolumn{2}{|c|}{ Composition (styrene/1/MMA) } & \multirow{2}{*}{$\frac{\text { Glass transition temperature }}{{ }^{\circ} \mathrm{C}}$} \\
\hline Polymer & $\bar{M}_{n} / 10^{4}$ & $\bar{M}_{w} / \bar{M}_{n}$ & by ${ }^{1} \mathrm{H}$ NMR & by GPC & \\
\hline PG-1 & 3.36 & 1.89 & $97 / 3 / 210$ & $97 / 3 / 222$ & 85,108 \\
\hline PG-2 & 3.60 & 1.92 & $94 / 5 / 260$ & $94 / 5 / 260$ & 90,113 \\
\hline PG-3 & 4.00 & 2.44 & $88 / 11 / 286$ & $88 / 11 / 297$ & 96,118 \\
\hline PG-4 & 4.23 & 2.49 & $88 / 11 / 308$ & $88 / 11 / 319$ & 96,119 \\
\hline
\end{tabular}

${ }^{\text {a }}$ Obtained by DSC at a heating rate of $10^{\circ} \mathrm{C} \mathrm{min}^{-1}$.

prepolymer. The molecular weight of PG-4 was higher than that of PG-3. The long period of graft copolymerization thus increases molecular weight of PMMA branch as well as block copolymerization ${ }^{14}$. The glass transition temperature $\left(T_{\mathrm{g}}\right)$ of the graft copolymers was measured by DSC. Two $T_{\mathrm{g}} \mathrm{s}$ observed are summarized in Table IV, as $85-96^{\circ} \mathrm{C}$ based on the polystyrene backbone and $108-119^{\circ} \mathrm{C}$ based on the PMMA branch, due to the formation of micro phase separation structure of the graft copolymer as conventional STMMA graft copolymers in the literature. ${ }^{23,25} T_{\mathrm{g}} \mathrm{s}$ increased with 1 in the prepolymer due to increasing PMMA composition in the graft copolymer. Possibly due to micro phase separation resulting from increase in the molecular weight of PMMA branches.

The graft copolymer can thus be prepared by the copolymerization of polymeric photoiniferter with MMA under photoirradiated.

\section{CONCLUSION}

A novel selenium-containing vinyl monomer, 1, was synthesized and polymerized with AIBN as radical initiator to afford corresponding homopolymers. From copolymerization with styrene, $r_{1}, r_{2}, Q_{2}$, and $e_{2}$ were $1.06,0.88,1.40$, and -1.06 , respectively. Photoirradiation of the copolymer of styrene and $\mathbf{1}$ as polymeric photoiniferter in the presence of MMA effectively afforded a graft copolymer composed of a polystyrene backbone and PMMA branches.

Acknowledgments. This work was supported by Grant-in-Aid for Scientific Research (No. 10650865) from the Ministry of Education, Science, Sports and 
Culture of Japan.

\section{REFERENCES}

1. S. Patai and Z. Rappoport, "The Chemistry of Organic Selenium and Tellurium Compounds", John Wiley \& Sons, New York, N.Y., 1986.

2. K. C. Nicolaou, Tetrahedron, 37, 4097 (1981).

3. D. Liotta, Acc. Chem. Res., 17, 28 (1984).

4. R. Michels, M. Kato, and W. Heitz, Makromol. Chem., 177, 2311 (1976).

5. W. Siebert and B. Asgarouladi, Z. Naturforsch, 306, 647 (1975).

6. V. T. Bregadze, V. T. Kampel, A. Y. Usiatinsky, O. B. Ponomareva, and N. N. Godovikov, J. Organometal, Chem., 233 , C33 (1982).

7. D. J. Sandman, M. Rubnet, and L. Samuelson, J. Chem. Soc., Chem. Commun., 1133 (1982)

8. M. Price and B. Bremer, J. Org. Chem., 32, 1655 (1967).

9. M. D. Bezoari, P. Kovacic, S. Gronowitz, and B. Hornfeldt, $J$. Polym. Sci., Polym. Lett., 19, 347 (1981).

10. E. Kobayashi, Y. Akiba, and S. Aoshima, J. Polym. Sci., Polym. Chem., 32, 1609 (1994).

11. D. L. Trumbo, Polym. Bull., 29, 165 (1992).

12. Y. Okamoto, R. Homsany, and T. Yano, Tetrahedron Lett., 2529
(1972).

13. T. Ando, T. S. Kwon, A. Kitagawa, T. Tanemura, S. Kondo, H. Kunisada, and Y. Yuki, Macromol. Chem. Phys., 197, 2803 (1996).

14. T. S. Kwon, S. Kondo, H. Kunisada, and Y. Yuki, Polym. J., 7, 559 (1998).

15. P. F. Rempp and P. J. Lutz, Compreh. Polym. Sci., 6, 403 (1989)

16. T. Otsu, T. Ogawa, and T. Yamamoto, Macromolecules, 19, 2087 (1986).

17. T. Otsu, K. Yamashita, and K. Tsuda, Macromolecules, 19, 287 (1986).

18. K. Yamashita, K. Ito, H. Tsuboi, S. Takahama, K. Tsuda, and T. Otsu, J. Appl. Polym. Sci., 40, 1445 (1990).

19. M. Niwa, N. Higashi, M. Shimizu, and T. Matsumoto, Makromol. Chem., 189, 2187 (1988).

20. M. Fineman and S. D. Ross, J. Polym. Sci., 5, 259 (1950).

21. T. Alfrey Jr. and C. C. Price, J. Polym. Sci., 5, 10 (1947).

22. G. Natta, F. Dauasso, and D. Sianesi, Makromol. Chem., 30, 238 (1959).

23. J. Brandrup and E. H. Immergut, "Polymer Handbook," 3rd ed, John Wiley \& Sons, New York, N.Y., 1989.

24. T. S. Kwon, S. Kondo, H. Kunisada, and Y. Yuki, unpublished results.

25. G. Allen and J. C. Bevington, "Comprehensive Polymer Science," 1st ed, Vol. 2, Pergamon Press, Oxford, 1989. 